\title{
EVALUASI KESESUAIAN LAHAN KOMODITI KAKAO (Theobroma cacao L.) BERDASARKAN DEPTAN (1997) DI DESA LUTUENG KECAMATAN MANE KABUPATEN PIDIE

\author{
Evaluation Land Suitability Of Cocoa Commodity (theobroma cacao l.) Based \\ Deptan (1997) In The Lutueng Village of Mane District Pidie
}

\author{
Hermawan Kurnia ${ }^{1}$, Zainabun ${ }^{1}$, Syamsidah Djuita ${ }^{1 *}$ \\ ${ }^{1}$ Program Studi Agroteknologi, Fakultas Pertanian Universitas Syiah Kuala
}

\begin{abstract}
Abstrak. Sesuai Kriteria DEPTAN (1997) ditemukan 2 Satuan Peta Lahan (SPL) yang di amati di lapangan dengan jenis tanah Ultisol, topografi mulai datar $(<8 \%)$ sampai landai $(8-15 \%)$, penggunaan lahan berupa hutan lindung dan pertanian lahan kering, keadaan drainase baik, kedalaman efektif 30-60 $\mathrm{cm}$. SPL 2 memiliki luas 3010,23 ha dan SPL 3 seluas 4255,39 ha dengan total luas lokasi penelitian 7265,62 ha. Analisis tingkat kesesuaian lahan aktual untuk tanaman kakao di Desa Lutueng Kecamatan Mane Kabupaten Pidie ditemukan pada SPL 2 dan SPL 3 adalah S3n. Tingkat kesuburan lahan pada SPL 2 dan SPL 3 tergolong rendah. Karakteristik lahan untuk pengembangan komoditi kakao dapat memberikan input perbaikan sehingga kesesuaian lahan potensial dapat dinaikkan kelas kesesuaiannya menjadi S1 dengan mengadakan perbaikan pengolahan tanah dan pemberian pupuk.
\end{abstract}

Kata Kunci: evaluasi, kakao, kesesuain, lahan komoditi

\begin{abstract}
According criteria of DEPTAN (1997) found 2 Soil Map Unit (SPL) were observed in the field with the Ultisol type, flat topography starts $(<8 \%)$ until the ramps $(8-15 \%)$, land use in the form of protected forest and dryland farming, a state of good drainage, effective depth of 30-60 cm. SPL 2 has an area of 3010.23 ha and SPL 3 area of 4255.39 ha with a total area of research is 7265.62 ha study site. Analysis of the level of actual land suitability for cocoa trees in the Lutueng village of Mane District of Pidie Regency match SPL 2 and 3 are S3N. Soil fertility level in the SPL 2 and 3 are low. Characteristics of land for the development of cocoa can provide input so that the land suitability of potential improvements can be raised by the $\mathrm{S} 1$ class compliance be made repairs tillage and fertilizer application.
\end{abstract}

Keywords: cocoa, evaluation, land of commodity, suitability

\section{PENDAHULUAN}

Tanaman kakao (Theobroma cacao L.) merupakan tanaman perkebunan yang berasal dari daerah tropis di Amerika Selatan yang membutuhkan lingkungan khusus untuk pertumbuhan yang baik dan tingkat produksi yang tinggi. Sistem perakaran yang lunak dan dangkal menyebabkan kakao membutuhkan persyaratan tanah yang subur dan bebas dari unsur-unsur yang bersifat racun (Panjaitan dan Sugiyono, 1989). Tanah yang baik untuk penanaman kakao mempunyai derajat kemasaman antara $6-7,5$. Tekstur tanah yang baik adalah lempung liat berpasir dengan komposisi 30- 40\% liat, 50\% pasir dan $10-20 \%$ debu (Setiawan, 2000).

Kesesuian lahan merupakan penggambaran tingkat kecocokan sebidang lahan untuk penggunaan lahan (jenis tanaman dan tingkat pengelolaan) tertentu. Kelas kesesuaian lahan suatau lokasi tergantung dari tipe penggunaan yang sedang

Corresponding author: djuita@ unsyiah.ac.id

JIM Pertanian Unsyiah - AGT, Vol. 2, No. 1, Februari 2017: 1-10 
dipertimbangkan (Sitorus, 1985). Kesesuaian lahan untuk penggunaan tertentu biasanya dievaluasi dengan menggunakan karakteristik lahan atau kualitas lahan.

Desa Lutueng merupakan daerah perkebunan dengan komiditi unggulan kopi dan kakao. Informasi kelas kesesuaian lahan untuk tanaman perkebunan di desa ini masih sangat terbatas. Oleh karena itu, penelitian ini perlu dilakukan guna untuk mengetahui kesesuaian lahan yang sesuai untuk tanaman kakao khususnya, mengingat daerah ini memiliki lahan yang luas dan berpotensi untuk pengembangan tanaman perkebunan. Dengan adanya informasi kelas kesesuaian lahan untuk pengembangan komoditi kakao diharapkan dapat dilakukan alternatif yang tepat guna meningkatkan produksi dan kesejahteraan masyarakat di desa Lutueung Kecamatan Mane Kabupaten Pidie.

Penelitian ini bertujuan untuk mengetahui luas dan tingkat kesesuaian lahan berdasarkan Kriteria Deptan (1997) untuk pengembangan komoditi kakao (Theobroma cacao L.) di Desa Lutueng Kecamatan Mane Kabupaten Pidie. Hasil dari penelitian ini diharapkan dapat menjadi acuan dan informasi bagi masyarakat dan Pemerintah Daerah dalam menerapkan rencana pengembangan komoditi kakao (Theobroma cacao L.) di Desa Lutueng Kecamatan Mane Kabupaten Pidie.

\section{METODE PENELITIAN}

Penelitian ini telah dilaksanakan di Desa Lutueng Kecamatan Mane Kabupaten Pidie pada bulan Mei sampai dengan Juli 2014. Analisis peta dilakukan di Laboratorium Penginderaan Jauh dan Kartografi Fakultas Pertanian Universitas Syiah Kuala. Analisis kimia tanah dilaksanakan di Laboratorium Kimia Tanah Fakultas Pertanian Universitas Syiah Kuala.

\section{MATERI DAN METODE}

Bahan yang digunakan dalam penelitian adalah Peta Jenis Tanah (Lampiran 5), Peta Kemiringan Lereng (Lampiran 6), dan Peta Penggunaan lahan (Lampiran 7) masing-masing dengan Skala 1:100.000. Bahan kimia yang digunakan di lapangan adalah Aquades, $\mathrm{HCl}$ dan $\mathrm{H}_{2} \mathrm{O}_{2}$. Alat yang digunakan dalam penelitian ini adalah sebagai berikut : (1) GPS (Global Positioning Sistem), (2) Bor tanah, (3) pH tancap, (4) Buku Munsell Soil Colour Chart, (5) Kantong plastik sampel, (6) Pipet tetes dan (7) Kamera.

Metode yang digunakan pada penelitian ini adalah metode survei deksriptif yang mengacu pada hasil pengamatan di lapangan dengan menggunakan kriteria Deptan (1997). Adapun tahapan pelaksanaan penelitian adalah sebagai berikut:

1. Tahap persiapan merupakan langkah awal guna memperoleh gambaran lokasi penelitian yaitu dengan pengumpulan studi pustaka dan peta dasar. Pembuatan peta kerja adalah dengan cara overlay Peta Jenis Tanah, Peta Kemiringan Lereng, dan Peta Penggunaan lahan yang selanjutnya menjadi Satuan Peta Lahan (SPL). Selanjutnya adalah persiapan perlengkapan dan pengurusan izin penelitian pada lokasi penelitian yang dilaksanakan pada tahapan survei awal.

2. Pengumpulan data meliputi data primer dan data sekunder. Data primer biasanya diperoleh langsung di lapangan seperti pengamatan tekstur tanah, warna tanah, $\mathrm{pH}$

Evaluasi kesesuaian Lahan Komoditi Kakao (theobroma cacao l.) 
tanah, drainase, lereng, erosi permukaan, batuan permukaan dan pengukuran kedalaman efektif. Data sekunder berupa data pelengkap seperti peta jenis tanah, peta kemiringan lereng, peta pengunaan lahan, studi pustaka, dan keadaan sosial ekonomi masyarakat pada lokasi penelitian.

3. Pengamatan lapangan dilaksanakan secara visual berdasarkan SPL yang sudah ditetapkan. Kegiatan yang dilakukan meliputi survei dan pengambilan sampel tanah di lokasi penelitian untuk dianalisis. Parameter fisika tanah yang diamati di lapangan dapat dilihat pada Tabel 1.

Tabel 1. Pengamatan Sifat Fisika Tanah di Lokasi Penelitian

\begin{tabular}{lll}
\hline No. & Karakteristik Lahan & \multicolumn{1}{c}{ Metode dan Alat yang Digunakan } \\
\hline 1 & Tekstur & Dipijat dengan jari \\
2 & Warna tanah & Munsell Soil Colour Chart \\
3 & pH tanah & pH tancap \\
4 & Drainase & Melihat genangan air di permukaan \\
5 & Kelerengan & Berdasarkan peta kemiringan lereng yang ada \\
6 & Erosi permukaan & Pengamatan lapisan atas \\
7 & Batuan permukaan & Berdasarkan \% batuan permukaan \\
8 & Kedalaman efektif & Pemboran sampai menyentuh lapisan padas/ bahan \\
& & induk
\end{tabular}

4. Untuk memperoleh hasil pengamatan yang lebih detail, diperlukan analisis laboratorium yang menyangkut sifat kimia tanah yang berhubungan dengan kesuburan tanah. Parameter kimia tanah yang dianalisis di laboratorium dapat dilihat pada Tabel 2.

Tabel 2. Sifat Kimia Tanah yang dianalisis di Laboratorium

\begin{tabular}{lll}
\hline No. & \multicolumn{1}{c}{ Sifat Kimia Tanah } & \multicolumn{1}{c}{ Metode Analisis } \\
\hline 1 & $\mathrm{pH}\left(\mathrm{H}_{2} \mathrm{O}\right)$ & Elektrimetrik \\
2 & C-Organik & Wallkey \& Black \\
3 & N-Total & Kjeldahl \\
4 & KTK & Ekstrak 1 NH $\mathrm{N}_{4} \mathrm{Oac} \mathrm{pH} 7$ \\
5 & P-Tersedia & Bray II \\
6 & K & HCl 25 \% \\
7 & DHL & Conduktivity \\
\hline
\end{tabular}

\section{HASIL DAN PEMBAHASAN}

Berdasarkan keterangan Geuchik Desa Lutueng Kecamatan Mane Kabupaten Pidie, desa tersebut hanya memiliki dua area perkebunan yang ditanami kakao dengan luas masing-masing 4 ha sampai 10 ha. Keberadaan perkebunan kakao berdasarkan Satuan Peta Lahan yang diamati di lapangan yaitu pada SPL 2 dan SPL 3, titik pengamatan sampel dapat dilihat pada Tabel 7 .

Evaluasi kesesuaian Lahan Komoditi Kakao (theobroma cacao l.)

Berdasarkan Deptan (1997) Di Desa Lutueng Kecamatan

Mane Kabupaten Pidie (Hermawan Kurnia, , Zainabun, Syamsidah Djuita)

Jurnal Ilmiah Mahasiswa Pertanian Unsyiah, Vol. 2, No. 1, Februari 2017: 1-10 
Tabel 7. Titik Pengamatan Sampel di Desa Lutueng Kecamatan Mane Kabupaten Pidie

\begin{tabular}{|c|c|c|c|}
\hline \multirow{2}{*}{ SPL } & \multirow{2}{*}{ Uraian } & \multicolumn{2}{|c|}{ Koordinat Sampel } \\
\hline & & LU & BT \\
\hline \multirow{3}{*}{ SPL 2} & $\begin{array}{l}\text { Hasil overlay : jenis tanah Ultisol, } \\
\text { topografi datar, penggunaan hutan } \\
\text { lindung. }\end{array}$ & $04^{\circ} 54^{\prime} 50^{\prime \prime}$ & $96^{\circ} 06^{\prime} 50^{\prime \prime}$ \\
\hline & $\begin{array}{l}\text { Karakteristik Lapangan : kedalaman } \\
\text { efektif tergolong dalam, kelerengan }\end{array}$ & & \\
\hline & $\begin{array}{l}\text { bergelombang, drainase agak terhambat, } \\
\text { pH tanah masam. }\end{array}$ & $04^{\circ} 55^{\prime} 45^{\prime \prime}$ & $96^{\circ} 06^{\prime} 40^{\prime \prime}$ \\
\hline \multirow{3}{*}{ SPL 3} & $\begin{array}{l}\text { Hasil overlay : jenis tanah Ultisol, } \\
\text { topografi landai, penggunaan hutan } \\
\text { lindung. }\end{array}$ & $04^{\circ} 58^{\prime} 50^{\prime \prime}$ & $96^{\circ} 09^{\prime} 30^{\prime \prime}$ \\
\hline & $\begin{array}{l}\text { Karakteristik Lapangan : kedalaman } \\
\text { efektif tergolong dalam, kelerengan }\end{array}$ & & \\
\hline & $\begin{array}{l}\text { landai, drainase sedang, } \mathrm{pH} \text { tanah } \\
\text { masam. }\end{array}$ & $04^{\circ} 57^{\prime} 20^{\prime \prime}$ & $96^{\circ} 10^{\prime} 30^{\prime \prime}$ \\
\hline
\end{tabular}

Sumber : Hasil Pengamatan Lapangan dan Analisis Satuan Peta Lahan, 2014

Tabel 7 menjelaskan bahwa pada SPL 2 dijumpai jenis tanahnya Ultisol dengan bentuk wilayah bergelombang $(8-15 \%)$ dimana fungsi kawasannya berupa Hutan Lindung. Sedangkan pada SPL 3 dijumpai jenis tanahnya Ultisol dengan bentuk wilayah datar sampai dengan landai $(<8 \%)$ dimana fungsi kawasannya juga berupa Hutan Lindung. Peta Lokasi Pengambilan Sampel dapat dilihat pada Lampiran 9.

Berdasarkan keterangan warga setempat, sebagian besar wilayah Desa Lutueng merupakan kawasan berstatus hutan lindung, hutan produksi terbatas atau hutan milik negara yang tidak bisa diakses oleh penduduk. Meskipun demikian, walaupun secara de facto sebagian besar desa adalah kawasan hutan negara, sebagian besar penduduk belum mengetahui batas-batas wilayah kawasan tersebut. Keberadaan hutan negara sendiri (hutan lindung khususnya) sering kali dipahami hanya dari keberadaan (plang pengumuman atau himbauan) untuk menjaga hutan. Pemasangan plang di tepi jalan tersebut kerap dimaknai oleh penduduk sebagai batasan hutan milik negara, sehingga terjadi salah pengertian bahwa tepian jalan dan lahan pemukiman merupakan kawasan hutan negara/ hutan lindung.

\section{Morfologi Lahan}

Hasil analisis sifat morfologi lahan di Desa Lutueng yang diamati di lapangan adalah : fisiografi, drainase, kedalaman efektif, kelerengan, batuan di permukaan, warna tanah, dan tekstur tanah, $\mathrm{pH}$ tanah dan bahan organik tanah. Sifat morfologi lahan tersebut erat hubungannya dengan sifat fisika tanah dan sifat kimia tanah, dimana sifat yang sangat mempengaruhi pertumbuhan dan produksi tanaman.

Evaluasi kesesuaian Lahan Komoditi Kakao (theobroma cacao l.)

Berdasarkan Deptan (1997) Di Desa Lutueng Kecamatan

Mane Kabupaten Pidie (Hermawan Kurnia, , Zainabun, Syamsidah Djuita)

Jurnal Ilmiah Mahasiswa Pertanian Unsyiah, Vol. 2, No. 1, Februari 2017: 1-10 


\section{Sifat Fisika Tanah}

Keadaan fisik tanah sangat penting untuk diperhatikan dalam pengembangan pertanian dan perkebunan karena memiliki peranan penting terhadap pertumbuhan dan produksi tanaman. Ritung et al. (2007) menyatakan sifat fisika tanah secara langsung dapat mempengaruhi kemampuan akar menembus tanah dan mempertahankan batang. Secara tidak langsung seperti penyediaan air dan aerasi yang cukup bagi perkembangan dan respirasi akar. Hasil analisis sifat fisika tanah di lapangan dapat dilihat pada Tabel 8.

Tabel 8. Karakteristik Sifat Fisik Tanah pada masing-masing Satuan Peta Lahan di Desa Lutueng Kecamatan Mane Kabupaten Pidie

\begin{tabular}{llll}
\hline \multirow{2}{*}{ No. } & \multirow{2}{*}{ Karakteristik Lahan } & \multicolumn{2}{c}{ Hasil Pengamatan } \\
\cline { 3 - 4 } & & \multicolumn{1}{c}{ SPL 2 } & \multicolumn{1}{c}{ SPL 3 } \\
\hline 1 & Tekstur & Lempung & Lempung berpasir \\
2 & Warna tanah & 10 YR 6/3 & 10 YR 5/4 \\
3 & pH tanah & Agak Terhambat & Sedang \\
4 & Drainase & $8-15 \%$ & $<8 \%$ \\
5 & Kelerengan & Ada & Ada \\
6 & Erosi permukaan & Tidak Ada & Tidak Ada \\
7 & Batuan permukaan & $>90 \mathrm{~cm}$ & $>90 \mathrm{~cm}$ \\
8 & Kedalaman efektif & & \\
\hline
\end{tabular}

Sumber : Hasil analisis lapangan, 2014

\section{Sifat Kimia Tanah}

Sifat kimia tanah merupakan faktor penting dalam menentukan kesuburan tanah. Analisis sifat kimia tanah di lakukan di laboratorium dan data hasil analisis dapat dilihat pada Tabel 9.

Tabel 9. Karakteristik Sifat Kimia Tanah pada masing-masing Satuan Peta Lahan di

\begin{tabular}{|c|c|c|c|c|c|c|c|c|c|}
\hline \multirow[b]{2}{*}{$\begin{array}{c}\text { SP } \\
\mathrm{L}\end{array}$} & \multirow[b]{2}{*}{ Kedalaman } & \multicolumn{2}{|c|}{$\mathrm{pH} \mathrm{1:2,5}$} & \multirow[b]{2}{*}{$\begin{array}{c}\text { DHL } \\
(\mathrm{mS} / \mathrm{cm})\end{array}$} & \multirow[b]{2}{*}{$\begin{array}{c}\text { C- } \\
\text { Organik } \\
(\%)\end{array}$} & \multirow[b]{2}{*}{$\begin{array}{l}\mathrm{N}- \\
\text { total } \\
(\%)\end{array}$} & \multirow{2}{*}{$\begin{array}{c}\mathrm{P}- \\
\text { tersedi } \\
\mathrm{a} \\
(\mathrm{ppm})\end{array}$} & \multicolumn{2}{|c|}{$\mathrm{NH}_{4} \mathrm{Oac} \mathrm{pH} 7$} \\
\hline & & $\mathrm{H}_{2} \mathrm{O}$ & $\mathrm{KCl}$ & & & & & $\begin{array}{c}\text { K-dd } \\
(\mathrm{me} / 100 \mathrm{~g} \\
)\end{array}$ & $\begin{array}{c}\text { KTK } \\
(\mathrm{me} / 100 \mathrm{~g} \\
)\end{array}$ \\
\hline \multirow{2}{*}{2} & $A_{1}: 0-20$ & 6,00 & 5,10 & & 2,29 & 0,27 & 2,71 & 0,70 & 15,60 \\
\hline & $: 20-40$ & 5,90 & 5,50 & & & 0,40 & 9,16 & 1,97 & 22,40 \\
\hline \multirow{2}{*}{3} & $\mathrm{~B}_{1}: 0-20$ & 6,20 & 5,70 & 0,10 & 7,69 & 0,89 & 1,43 & 0,30 & 26,80 \\
\hline & $B_{2}: 20-40$ & 6,30 & 5,80 & 0,10 & 6,33 & 0,73 & 1,52 & 0,22 & 25,20 \\
\hline
\end{tabular}

Sumber : Hasil analisis laboratorium, 2014

Desa Lutueng Kecamatan Mane Kabupaten Pidie

Karakteristik Lahan dan Kesesuaian Komoditi Kakao berdasarkan Kriteria DEPTAN (1997)

Karakteristik lahan yang digunakan berdasarkan kriteria DEPTAN (1997) mewakili kualitas lahan berdasarkan sifat fisika tanah yaitu tekstur, warna tanah, $\mathrm{pH}$

Evaluasi kesesuaian Lahan Komoditi Kakao (theobroma cacao l.)

Berdasarkan Deptan (1997) Di Desa Lutueng Kecamatan

Mane Kabupaten Pidie (Hermawan Kurnia, , Zainabun, Syamsidah Djuita)

Jurnal Ilmiah Mahasiswa Pertanian Unsyiah, Vol. 2, No. 1, Februari 2017: 1-10 
tanah, drainase, kelerengan, erosi permukaan, batuan permukaan dan kedalaman efektif. Penentuan nilai-nilai karakteristik lahan yang berhubungan sifat kimia tanah seperti derajat keasaman $(\mathrm{pH}), \mathrm{C}$-organik, kapasitas tukar kation (KTK), N-total, P-tersedia, kalium (K) dan DHL.

Tabel 10. Evaluasi Kesesuaian Komoditi Kakao berdasarkan Kriteria DEPTAN (1997) di Desa Lutueng Kecamatan Mane Kabupaten Pidie

\begin{tabular}{|c|c|c|c|c|c|c|}
\hline \multirow{2}{*}{ No } & \multirow{2}{*}{\multicolumn{2}{|c|}{ Kualitas/ Karakteristik Lahan }} & \multicolumn{2}{|c|}{ SPL 2} & \multicolumn{2}{|c|}{ SPL 3} \\
\hline & & & Nilai & Hasil & Nilai & Hasil \\
\hline \multirow[t]{2}{*}{1} & Temperatur & & & & & \\
\hline & a. Rata-Rata Tahunan & ${ }^{\circ} \mathrm{C}$ & $25-28$ & S1 & $25-28$ & S1 \\
\hline \multirow[t]{2}{*}{2} & $\begin{array}{l}\text { Ketersediaan air } \\
\text { a. Bulan Kering }\end{array}$ & & 2,7 & $\mathrm{~S} 2$ & 2,7 & $\mathrm{~S} 2$ \\
\hline & Tahun & $\mathrm{Mm}$ & 2061 & S2 & 2061 & S1 \\
\hline \multirow[t]{4}{*}{3} & Media Perakaran & & & & & \\
\hline & a. Drainase Tanah & & Sedang & S2 & Sedang & $\mathrm{S} 2$ \\
\hline & b. Tekstur & & Lempung & S1 & $\begin{array}{l}\text { Lempung } \\
\text { Berpasir }\end{array}$ & $\mathrm{S} 2$ \\
\hline & c. Kedalaman Efektif & $\mathrm{Cm}$ & $>90$ & $\mathrm{~S} 1$ & $>90$ & S1 \\
\hline \multirow[t]{4}{*}{4} & Retensi hara & & & & & \\
\hline & a. KTK tanah & & 19 & & 27,2 & \\
\hline & b. pH Tanah & & 5,9 & S1 & 6,1 & S1 \\
\hline & c. C-Organik & $\%$ & 2,15 & & 5,93 & \\
\hline \multirow[t]{2}{*}{5} & Kegaraman & & & & & \\
\hline & a. Salinitas & $\mathrm{mmhos} / \mathrm{cm}$ & 0,16 & $\mathrm{~S} 1$ & 0,12 & $\mathrm{~S} 1$ \\
\hline \multirow[t]{3}{*}{6} & Hara tersedia & & & & & \\
\hline & a. Total N & & 0,25 & S1 & 0,68 & S1 \\
\hline & b. $\mathrm{P}_{2} \mathrm{O}_{5}$ & & 5,18 & S3 & 1,41 & S3 \\
\hline \multirow[t]{5}{*}{7} & Terrain/ Potensi & & & & & \\
\hline & $\begin{array}{l}\text { MeKanisasi } \\
\text { a. Lereng }\end{array}$ & $\%$ & $8-15$ & $\mathrm{~S} 2$ & $<8$ & S1 \\
\hline & & & & & Tidak & \\
\hline & b. Batuan Permukaan & $\%$ & Tidak Ada & $\mathrm{S} 1$ & Ada & S1 \\
\hline & c. Singkapan Batuan & $\%$ & Tidak Ada & S1 & $\begin{array}{l}\text { Tidak } \\
\text { Ada }\end{array}$ & S1 \\
\hline 8 & Tingkat Bahaya Erosi & $\mathrm{E}$ & $\mathrm{c} 1$ & $\mathrm{~S} 1$ & $\mathrm{c} 1$ & $\mathrm{~S} 1$ \\
\hline 9 & Bahaya Banjir & $\mathrm{B}$ & $\mathrm{f} 1$ & $\mathrm{~S} 2$ & fo & $\mathrm{S} 1$ \\
\hline \multicolumn{3}{|c|}{ Kesesuaian Lahan Aktual } & & S3n & & S3n \\
\hline
\end{tabular}

Evaluasi kesesuaian Lahan Komoditi Kakao (theobroma cacao l.)

Berdasarkan Deptan (1997) Di Desa Lutueng Kecamatan

Mane Kabupaten Pidie (Hermawan Kurnia, , Zainabun, Syamsidah Djuita)

Jurnal Ilmiah Mahasiswa Pertanian Unsyiah, Vol. 2, No. 1, Februari 2017: 1-10 
Berdasarkan hal tersebut, maka sampel tanah yang diambil dalam penelitian ini adalah tanah yang berada pada kedalaman antara $20-60 \mathrm{~cm}$, karena tanaman kakao merupakan tanaman tahunan. Tingkat kesesuaian komoditi kakao dapat diketahui setelah dilakukan pembandingan antara karakteristik lahan di Desa Leuteung dengan syarat tumbuh tanaman kakao berdasarkan kriteria DEPTAN (1997) yang dapat dilihat pada Tabel 10.

\section{Penilaian Kesesuaian Lahan Aktual}

Kesesuaian lahan aktual atau kesesuaian lahan saat ini adalah kelas kesesuaian lahan yang dihasilkan berdasarkan data hasil pengamatan dan analisis lapangan maupun laboratorium. Pada lahan tersebut belum dilakukan perbaikan/ pengelolaan untuk mengatasi kendala atau faktor-faktor pembatas di lapangan.

Hasil dari pembandingan (matching) secara aktual pada kedua titik SPL untuk tanaman kakao di Desa Lutueng dapat digolongkan ke dalam sub kelas kesesuaian lahan yaitu sesuai marginal (S3) dengan faktor pembatas drainase tanah dan ketersediaan P pada SPL 2, sedangkan SPL 3 faktor pembatas berupa ketersediaan P dan bahaya erosi. Faktor pembatas yang dijumpai di lapangan tergolong tinggi namun bila dilakukan upaya perbaikan masih ada kemungkinan kesesuaian lahan dapat kembali pulih. Pada aplikasinya, untuk melakukan upaya perbaikan memerlukan input yang tinggi seperti pembuatan drainase, penyediaan unsur hara $\mathrm{P}$ dan upaya tanaman penutup tanah (cover crop) untuk mengurangi tingkat erosi. Hasil evaluasi kesesuaian lahan aktual untuk tanaman kakao secara lengkap dapat dilihat pada Tabel 11.

Tabel 11. Hasil Evaluasi Kesesuaian Lahan Aktual untuk Komoditi Kakao di Desa Lutueng Kecamatan Mane Kabupaten Pidie

\begin{tabular}{ccccc}
\hline \multirow{2}{*}{ SPL } & $\begin{array}{c}\text { Kesesuaian } \\
\text { Lahan Aktual }\end{array}$ & \multirow{2}{*}{ Faktor Pembatas } & \multicolumn{2}{c}{ Luas } \\
\cline { 3 - 5 } & S3n & Ketersediaan Hara & 3010,23 & 41,43 \\
3 & S3n & Ketersediaan Hara & 4255,39 & 58,57 \\
\hline \multicolumn{3}{c}{ Total } & 7265,62 & 100 \\
\hline
\end{tabular}

Sumber : Data diolah, 2014

Keterangan :

$\mathrm{n}=$ ketersediaan hara

\section{Penilaian Kesesuaian Lahan Potensial}

Kesesuaian lahan potensial adalah kesesuaian lahan yang telah dilakukan usaha perbaikan. Usaha perbaikan yang dilakukan harus sejalan dengan tingkat penilaian kesesuaian lahan yang akan dilaksanakan. Kelas kesesuaian lahan potensial dapat ditingkatkan kelas kesesuaiannya dengan cara memberikan input teknologi untuk menanggulangi faktor pembatas yang ada. Tingkat perbaikan yang diberikan adalah dalam bentuk Low input (Li), Medium input (Mi) dan High input (Hi).

Evaluasi kesesuaian Lahan Komoditi Kakao (theobroma cacao l.)

Berdasarkan Deptan (1997) Di Desa Lutueng Kecamatan

Mane Kabupaten Pidie (Hermawan Kurnia, , Zainabun, Syamsidah Djuita)

Jurnal Ilmiah Mahasiswa Pertanian Unsyiah, Vol. 2, No. 1, Februari 2017: 1-10 
Hasil evaluasi kesesuaian lahan aktual sebelumnya telah ditemukan faktor pembatas utama yang menyebabkan lahan tersebut tidak sesuai digunakan yaitu drainase tanah, ketersediaan $\mathrm{P}$ dan bahaya erosi. Pada kedua SPL yang diamati, ternyata secara potensial masih dapat ditingkatkan kelasnya menjadi S1. Karena upaya perbaikan masih dapat dilakukan walau input yang diberikan tergolong tinggi. Pembuatan drainase dibeberapa tempat yang rawan pada SPL 2 dan penanaman tanaman penutup tanah atau naungan pada SPL 3 dapat mengembalikan potensi kesesuaian lahan terhadap daya tumbuh dan produktivitas tanaman kakao di Desa Lutueng Kecamatan Mane Kabupaten Pidie. Adapun hasil evaluasi kesesuaian lahan secara potensial secara lengkap dapat dilihat pada Tabel 12.

Tabel 12. Hasil evaluasi kesesuaian lahan potensial untuk Komoditi Kakao di Desa Lutueng Kecamatan Mane Kabupaten Pidie

\begin{tabular}{|c|c|c|c|c|c|}
\hline SPL & $\begin{array}{c}\text { Kesesuaian } \\
\text { Lahan } \\
\text { Aktual }\end{array}$ & $\begin{array}{c}\text { Faktor } \\
\text { Pembatas }\end{array}$ & $\begin{array}{l}\text { Usaha } \\
\text { Perbaikan }\end{array}$ & $\begin{array}{l}\text { Tingkat } \\
\text { Teknologi }\end{array}$ & $\begin{array}{c}\text { Kesesuaian } \\
\text { Lahan } \\
\text { Potensial }\end{array}$ \\
\hline 2 & S3n & $\begin{array}{l}\text { Ketersediaan } \\
\text { Hara }\end{array}$ & Tambahan hara & Low Input & S1 \\
\hline 3 & S3n & $\begin{array}{l}\text { Ketersediaan } \\
\text { Hara }\end{array}$ & Tambahan hara & Low Input & S1 \\
\hline
\end{tabular}

Sumber : Data diolah, 2014

\section{Penilaian Status Kesuburan Tanah}

Kesuburan tanah merupakan kemampuan atau kualitas suatu tanah menyediakan unsur-unsur hara tanaman dalam jumlah yang mencukupi kebutuhan tanaman. Penilaian kesuburan tanah di lokasi penelitian didasarkan pada data hasil analisis tanah yang meliputi parameter: KTK, P-tersedia, dan C-Organik. Hasil penilaian sifat-sifat tanah yang berhubungan dengan potensi kesuburan tanah pada tiap satuan peta lahan di Desa Lutueng Kecamatan Mane Kabupaten Pidie. Harkat penilaian kesuburan tanah tersebut mengacu pada kriteria TOR P3MT (PPT, 1983). Untuk lebih jelasnya dapat dilihat pada Tabel 13.

Tabel 13. Harkat kesuburan tanah pada masing-masing satuan peta lahan di Desa Lutueng Kecamatan Mane Kabupaten Pidie

\begin{tabular}{ccccc}
\hline SP & \multirow{2}{*}{ KTK } & $\begin{array}{c}\text { P- } \\
\text { tersedia }\end{array}$ & C-org & Tingkat Kesuburan \\
\hline 2 & S & SR & S & Sedang \\
3 & T & SR & ST & Tinggi \\
\hline
\end{tabular}

Keterangan

ST : Sangat Tinggi $\quad$ T : Tinggi $\quad$ S : Sedang $\quad$ R : Rendah $\quad$ SR : Sangat Rendah

Evaluasi kesesuaian Lahan Komoditi Kakao (theobroma cacao l.)

Berdasarkan Deptan (1997) Di Desa Lutueng Kecamatan

Mane Kabupaten Pidie (Hermawan Kurnia, , Zainabun, Syamsidah Djuita)

Jurnal Ilmiah Mahasiswa Pertanian Unsyiah, Vol. 2, No. 1, Februari 2017: 1-10 


\section{KESIMPULAN}

Analisis tingkat kesesuaian lahan untuk tanaman kakao di Desa Lutueng Kecamatan Mane Kabupaten Pidie adalah kelas kesesuaian lahannya adalah sesuai marginal (S3) dengan faktor pembatas ketersediaan hara. Tingkat kesuburan lahan pada SPL 2 tergolong sedang, sedangkan pada SPL 3 tergolong tinggi dan cocok untuk pengembangan komoditi kakao. Karakteristik lahan untuk pengembangan komoditi kakao dapat memberikan input perbaikan untuk kesesuaian lahan agar dapat dinaikkan kelas kesesuaiannya dengan mengadakan perbaikan pengolahan tanah dan pemberian pupuk.

\section{DAFTAR PUSTAKA}

Arsyad, S. 1989. Konservasi Tanah dan Air. IPB. Bogor.

Badan Pusat Statistik (BPS) Kabupaten Pidie. 2012. Kabupaten Pidie dalam Angka. Pidie.

Departemen Pertanian (DEPTAN). 1997. Kriteria Kesesuaian Tanah dan Iklim Tanaman Pertanian. Jakarta.

Dinas Pertanian Tanaman Pangan dan Hortikultura. 2006. Laporan Tahunan. Kabupaten Pidie.

Djaenudin, D., Marwan, H., Subagjo, H., dan A. Hidayat. 2011. Petunjuk Teknis Evaluasi Lahan Untuk Komoditas Pertanian. Balai Besar Litbang Sumberdaya Lahan Pertanian, Badan Litbang Pertanian, Bogor.

Djaenudin, D., Marwan, H., Subagjo, H., Mulyani, A. dan Suharta. 2003. Kriteria Kesesuaian Lahan Untuk Komoditas Pertanian. Pusat Pertanian Tanah dan Agroklimat, Badan Pengembangan Penelitian dan Pengembangan Pertanian. Jakarta.

FAO. 1976. A Framework for Land Evaluation. Soil Resource Management and Conservation Service Land and Water Development Division.

Liyanda, M., Karim, A., Abubakar, Y. 2012. Analisis Kriteria Kesesuaian Lahan Terhadap Produksi Kakao pada Tiga Klaster Pengembangan di Kabupaten Pidie. Jurnal Agrista. Vol:16 No.2

Mega, I.M., Dibia, I.N., Adi, I.G.P.R, Kusmiyarti, T.B. 2010. Buku Ajar Klasifikasi Tanah dan Kesesuaian Lahan. Program Studi Agroekoteknologi Fakultas Pertanian Universitas UDAYANA. Denpasar.

Panjaitan, A. dan Sugiyono. 1989. Hubungan antara Kesuburan Tanah dan Produksi Kakao di Sumatera Utara. Presiding Kongres Nasional V. Hal : 285 - 286. Himpunan Ilmu Tanah Indonesia. Medan.

Safuan, L.O., Kandari, A.M., Natsir, M. 2013. Evaluasi Kesesuaian Lahan Tanaman Kakao (Theobroma cacao L.) berdasarkan Analisis Data Iklim Menggunakan Aplikasi Sistem Informasi Geografi. Jurnal Agroteknos. Vol. 3, No. 2, Hal : 80 85. Fakultas Pertanian Universitas Haluoleo. Kendari.

Setiawan, L.A. 2000. Penghijauan dengan Tanaman Potensial. Penebar Swadaya. Hal : $64-65$. Jakarta.

Evaluasi kesesuaian Lahan Komoditi Kakao (theobroma cacao l.)

Berdasarkan Deptan (1997) Di Desa Lutueng Kecamatan

Mane Kabupaten Pidie (Hermawan Kurnia, , Zainabun, Syamsidah Djuita)

Jurnal Ilmiah Mahasiswa Pertanian Unsyiah, Vol. 2, No. 1, Februari 2017: 1-10 
Siregar, T.H.S., Riadi dan Nuraeni, L. 2005. Budidaya, Pengolahan dan Pemasaran Coklat. Penebar Swadaya. Jakarta.

Sitepu, A. 2007. Evaluasi Kesesuaian Lahan untuk Tanaman Kelapa Sawit (Elaeis quenensis Jacq), Coklat (Theobroma cacao) dan Karet (Havea brasiliensis) di Desa Belinteng Kecamatan Sei Bingei Kabupaten Langkat. Skripsi. Fakultas Pertanian Universitas Sumatera Utara.

Sitorus, S. 1985. Evaluasi Sumberdaya Lahan. Tarsito. Bandung.

Sundjaya. 2015. Kajian Etnografi dan Perencanaan Masyarakat Pengelola Hutan Desa di Mukim Lutueng Kabupaten Pidie Aceh. Pusat Kajian Antropologi Universitas Indonesia.

Syahputra, M.A.S. 2010. Evaluasi Kesesuaian Lahan untuk Tanaman Kakao Menurut LREP di Kecamatan Glumpang Tiga Kabupaten Pidie. Jurusan Budidaya Pertanian Fakultas Pertanian Universitas Syiah Kuala. Banda Aceh.

Term of Reference (TOR) Survey Kapabilitas Tanah Pusat Penelitian Tanah P3MT. 1983.

Evaluasi kesesuaian Lahan Komoditi Kakao (theobroma cacao l.)

Berdasarkan Deptan (1997) Di Desa Lutueng Kecamatan

Mane Kabupaten Pidie (Hermawan Kurnia, , Zainabun, Syamsidah Djuita)

Jurnal Ilmiah Mahasiswa Pertanian Unsyiah, Vol. 2, No. 1, Februari 2017: 1-10 